\title{
Fighting for mates: the importance of individual size in mating contests in rocky shore littorinids
}

\author{
Terence P. T. $\mathrm{Ng}^{1} \cdot$ Mark S. Davies $^{2} \cdot$ Richard Stafford $^{3} \cdot$ Gray A. Williams ${ }^{1}$
}

Received: 24 June 2015 / Accepted: 20 January 2016 / Published online: 15 February 2016

(C) Springer-Verlag Berlin Heidelberg 2016

\begin{abstract}
Studies of mating contests have reported how traits (e.g. body size) related to resource-holding potential (RHP) and strategies to assess RHP and resource value influence contest outcome in many taxa but are rare in the Gastropoda. The influence of male size (as an index of RHP) and female size (as a measure of resource value) on contest outcome was investigated in two littorinid snails, Echinolittorina malaccana and E. radiata, in Hong Kong during May-June 2013. In these snails, contests between males take the form of a 'challenger' attempting to take over the copulation position occupied by a 'defender'. Both challengers and defenders were, generally, smaller than the females in both species. In both species, the larger the challenger relative to the defender, the more likely he would replace the defender in the copulation position. The challengers were, however, more successful in E. radiata, as
\end{abstract}

Responsible Editor: J. Grassle.

Reviewed by J. H. Christy and an undisclosed expert.

Electronic supplementary material The online version of this article (doi:10.1007/s00227-016-2824-z) contains supplementary material, which is available to authorized users.

Gray A. Williams

hrsbwga@hku.hk

Terence P. T. Ng

tptng@hku.hk

1 The Swire Institute of Marine Science and School of Biological Sciences, The University of Hong Kong, Pokfulam Road, Hong Kong SAR, China

2 Faculty of Applied Sciences, University of Sunderland, Sunderland, UK

3 Faculty of Science and Technology, Bournemouth University, Bournemouth, UK they generally challenged defenders that were smaller than themselves, suggesting an ability to detect rival size before entering into a contest in this species. When sizes of the contestants were similar, defenders were more likely to win contests in E. malaccana but not in E. radiata. Evidence for pure self-assessment of RHP and the ability to assess resource value in challengers was found in E. malaccana. Different fighting strategies appear to have evolved in these congeneric marine snail species, and decisions based on male and female sizes play an important role in determining male reproductive success.

\section{Introduction}

Males of many species fight for the opportunity to mate (Andersson 1994; Hardy and Briffa 2013). Males, however, differ in size, development of weaponry, energetic and physiological state and recent history of wins and losses, any of which may affect their fighting ability, or resourceholding potential (RHP; Parker 1974). Contests are also settled based on the strategies males use to assess the RHP, such that males will decide to persist or retreat in a contest based on their own RHPs or the perceived difference in RHPs between themselves and their rivals (Taylor and Elwood 2003; Arnott and Elwood 2009). In some contests, males differ in their roles, such as in challenger-defender contests where one male (the defender) occupies a mate and the other male (the challenger) attempts to take over his position (also described as intruder-owner contests, when the defender occupies a physical space such as a territory or a burrow rather than a mate, Arnott and Elwood 2008). In such a scenario, the defenders are often able to resist takeovers, and this success is often attributed to the defenders being highly motivated to maintain the females (to hold 
on to their resource) given their already high investment in securing the female (Kokko et al. 2006; Arnott and Elwood 2008). The difference in RHP among males and the strategies males use to assess RHP and resource values, therefore, play an important role in determining the outcome of male-male contests (reviewed by Arnott and Elwood 2008, 2009).

Whilst such mating contests have been intensively studied in insects (Hardy and Briffa 2013), studies are relatively scarce in the second most species-rich invertebrate class, the Gastropoda. Bradshaw-Hawkins and Sander (1981) have reported male-male combat in the form of physical aggression in the dioecious marine snail, Strombus pugilis. Similar observations, where two males push against each other on top of a female, have also been recorded in some littorinid snails (Gibson 1965; Zahradnik et al. 2008; Ng and Williams 2014); in particular, Ng and Williams (2014) showed that large males have a size advantage over smaller males in access to females of the mangrove littorinid, Littoraria ardouiniana. Size may, therefore, also be an important component of RHP in marine dioecious gastropods.

Littorinid snails (family Littorinidae) are among the most common dioecious gastropods and inhabit most intertidal habitats worldwide (Reid 1986, 1989; Reid et al. 2012). Tropical littorinids dominate the high shore environment have their activity (including mating) windows relatively narrow due to the limited time awash by tides (Mak 1996; McQuaid 1996). Intense competition for mates in these snails is, therefore, anticipated due to the limited time available to find and copulate with a mate. Males are the active sex and follow females' mucus trails to locate and mount them before initiating copulation (Gibson 1965; Erlandsson and Kostylev 1995; Ng et al. 2011, 2013; Saltin et al. 2013). Female size is also important, as large females are usually favoured by males because fecundity generally increases with size in these snails (Erlandsson and Johannesson 1994; Zahradnik et al. 2008; Ng and Williams 2012).

The present study examined contest behaviour in two rocky shore littorinids, Echinolittorina malaccana and E. radiata. These two species are sympatric and occur at high densities in the Indo-West Pacific, and in Hong Kong, $E$. radiata has a more female-biased sex ratio than $E$. malaccana (Mak 1996). In littorinid snails, mating contests generally follow one of two scenarios (see $\mathrm{Ng}$ and Williams 2014): either (1) when two males simultaneously mount a female the males push against each other and the one that successfully displaces the other stays and copulates with the female; or (2) when one male (the defender) is copulating with a female and another (the challenger) encounters the pair and attempts to push away the defender, this challenger may or may not successfully take over the copulation position. This paper focuses on the second, more common scenario, as shell mounting before copulation, in general, only takes a few seconds ( $\mathrm{Ng}$ unpubl. observation). Specifically, we predicted that (1) contests would be less intense in $E$. radiata due to the likelihood of more mating opportunities for males in the female-biased populations; (2) that defenders were more likely to win contests when their sizes were similar to or larger than the challengers; and (3) that male (RHP) and female sizes (resource value) would influence both contest outcome and duration.

\section{Materials and methods}

\section{Study site}

All work was conducted in late May to early June 2013 (the reproductive season of E. malaccana and E. radiata, Mak 1996) at the Cape d' Aguilar Marine Reserve, Hong Kong $\left(22^{\circ} 12^{\prime} 27^{\prime \prime} \mathrm{N}, 114^{\circ} 15^{\prime} 36^{\prime \prime} \mathrm{E}\right)$. Both species occur at high densities (generally $>400$ individuals $\mathrm{m}^{-2}$ ) on the high shore level, and their distributions largely overlap, with E. malaccana being slightly higher on the shore than $E$. radiata (Mak 1996; Mak and Williams 1999). These snails are inactive at low tide, become active and move up the shore when awash by the rising tide, and then move back down the shore while awash on the ebbing tide to become inactive again when emersed (Williams 1994; Stafford et al. 2007; Marshall et al. 2010). Preliminary observations showed that mating activities of both species were most intense during rising tides (the 'mating activity window') and were greatly reduced during ebbing tides.

\section{Occurrence and intensity of contests}

Field observations were conducted to investigate whether contests occurred throughout the mating activity window of the two littorinids. To ensure maximum capture of mating contests for a high resolution of the temporal pattern, while avoiding repeated counting of the same events, observations were conducted every five minutes (as preliminary observations showed contest durations in both species generally last $<5 \mathrm{~min}$ ) from when the tide first wetted the littorinids and stimulated them to move upshore (tidal height: 1.7-1.8 $\mathrm{m}$ above Chart Datum), until the tide approached its maximum height ( $2 \mathrm{~m}$ above Chart Datum, i.e. the rising tide). A $0.25 \mathrm{~m} \times 0.25 \mathrm{~m}$ quadrat was placed in the zone where the two species overlapped and where high densities of wet (and hence active) individuals were found in four $4-5 \mathrm{~m}$ horizontal sections of the shore $(6-10 \mathrm{~m}$ apart, separated by sand or boulders). Snails were distributed at slightly different tidal heights in the sections due to local topographic influences, and hence, survey starting times varied in the sections. The number of individuals, 
mating pairs and pairs involved in contests was recorded, as was the number of heterospecific 'mating' pairs.

\section{Effect of male and female sizes on contest outcome and duration}

Field observations were conducted during rising tides to investigate the influence of male and female sizes on contest outcome and duration in the two species. Contest duration started when an intruding male mounted a mating pair and ended when the unsuccessful contestant or 'loser' left the female ( $n=30$ per species). All snails involved in the contests were taken to the laboratory where species, sex (determined by the presence or absence of a penis as observed under a dissection microscope) and sizes (shell length $[\mathrm{SL}] \pm 0.1 \mathrm{~mm}$, vernier callipers) of the successful contestant or 'winner' (snail in the copulation position at the end of the contest), the unsuccessful contestant or 'loser' of the contest events and the passive individual (i.e. snail over which the contestants were competing) were recorded. All snails were returned to the shore after examination. A previous study on another littorinid species, $L$. ardouiniana, showed that defenders rapidly withdrew their penises when pushed by intruding males ( $\mathrm{Ng}$ and Williams 2014). Based on this observation, we assumed that the defenders retreating from the copulation position (i.e. in cases where defenders were losers) were a result of the action of the challengers rather than completion of copulation with the female.

\section{Statistical analyses}

To compare the variations in mating intensity and proportions of matings that involved contests among the four shore sections in the two species, mixed-model ANOVAs (species as a fixed factor and shore as a random factor) were performed. Since mating durations are generally $>5$ min (i.e. longer than the 5 -min survey intervals) but finished within $30 \mathrm{~min}$ ( $\mathrm{Ng}$ et al. in submission), we used the mean proportion of individuals that were mating in every 30-min interval as replicates to compare mating intensity between the two species. Proportional data were arcsine-square-root-transformed, and data were checked for homogeneity of variances prior to analyses (Levene's test). Where the assumption of homogeneity was violated (data for matings that involved contests), an ANOVA was still performed (given the large sample size), but with a more conservative significance level $(p<0.01)$.

Two-tailed binomial tests were performed to investigate whether the ratio of contests that involved larger challengers and smaller defenders to those that involved smaller challengers and larger defenders deviated from 1:1. The same statistical approach was applied to investigate whether the ratio of contests that involved larger females and smaller defenders or challengers, or those that involved smaller females and larger defenders or challengers deviated from 1:1. Binary logistic regression analyses were conducted to investigate whether female size and the relative difference between the size of males affected contest outcome (win or lose; following Briffa et al. 2013).

A series of linear regression analyses, with the contest durations as the dependent variable against sizes of the winners and losers in both successful and unsuccessful takeovers, were conducted to investigate the assessment strategies of RHP in males (following Arnott and Elwood 2009). Contest durations were log-transformed prior to analyses to achieve normality. Comparisons between the relationships in this statistical approach were used to test three RHP assessment strategies of males: (1) pure self-assessment in which each contestant only has information about its own RHP, and both contestants incur a cost from their own actions; (2) cumulative assessment in which contestants terminate a contest when accrued costs due to damages inflicted by an opponent exceed a threshold, and hence, the decision to retreat is influenced by the RHPs of both contestants; and (3) mutual assessment in which a contestant assesses the difference in RHP between itself and its opponent, and hence, the one with the lower perceived RHP can rapidly terminate a contest in order to reduce time, energy expenditure and risk of injury from engaging in the contest (see Taylor and Elwood 2003 and Arnott and Elwood 2009 for detailed illustrations). The same statistical approach, using contest durations in successful and unsuccessful takeovers against female size, was also followed to investigate the males assessment strategies of resource (female) value (i.e. whether the challenger or the defender possessed the ability to gather information about the resource, following Arnott and Elwood 2008). Since there were only three cases where the defender won the contest in E. radiata, analyses of unsuccessful takeovers in this species were not performed. All statistical tests were performed using SPSS 16.0.

\section{Results}

\section{Contest behaviour}

During a contest, the defender was attached on the right side of the female, parallel to the substratum (i.e. in the copulation position) and typically perpendicular to the challenger (see supplementary materials S1 and S2 for videos, with descriptions of the contest behaviour in E. malaccana and E. radiata, respectively). The challenger appeared to be more 'aggressive' than the defender and readily used his snout, aimed at the foot of the defender, to attempt to 


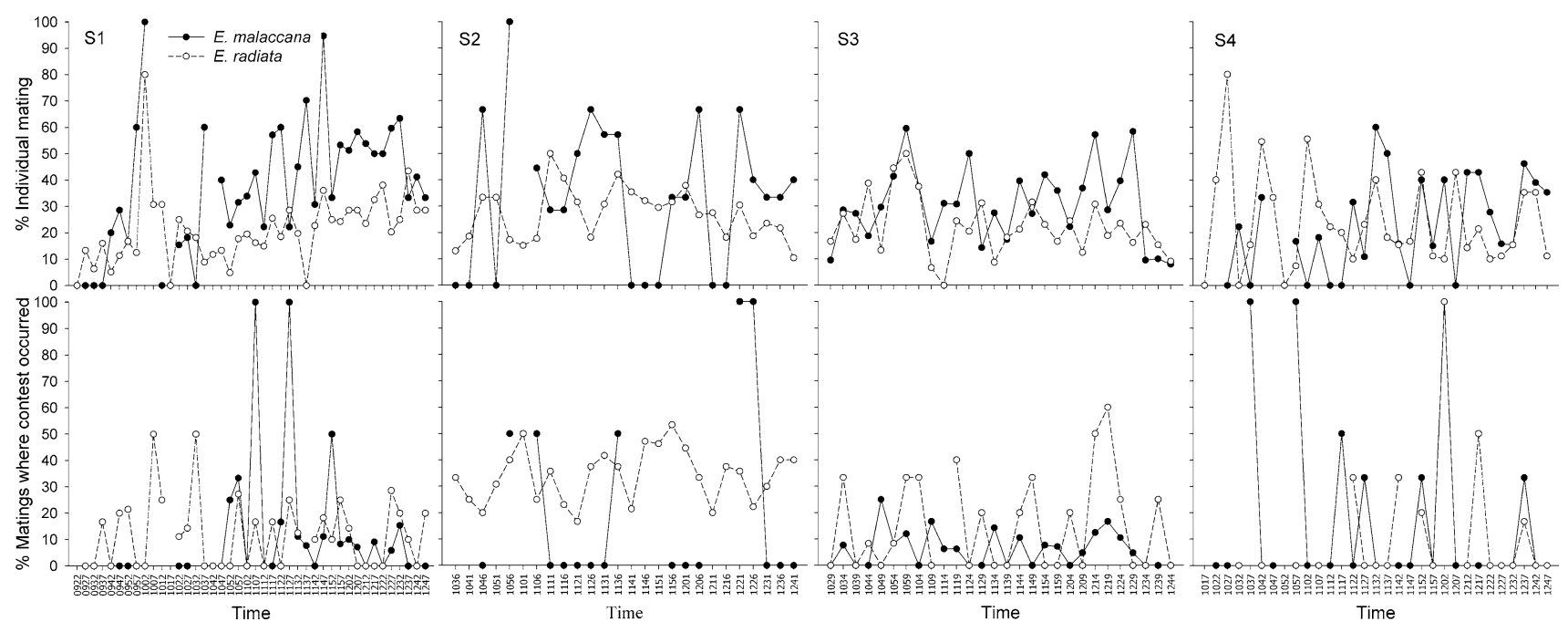

Fig. 1 Percentage of individuals mating (upper row) and of matings where contests occurred (lower row) for E. malaccana and E. radiata throughout the mating activity window (i.e. rising tide) on four shore sections (S1-S4) at Cape d'Aguilar Marine Reserve, Hong Kong. Measurements were taken every $5 \mathrm{~min}$ from time when snails were wetted and hence activated by the rising tide
Table 1 Number of cases where challenger was larger or smaller than defender in contests in E. malaccana and $E$. radiata

\begin{tabular}{llccc}
\hline Species & Challenger $>$ defender & Challenger $<$ defender & Binomial test $(p$ value $)$ & $n$ \\
\hline E. malaccana & 17 & 13 & 0.585 & 30 \\
E. radiata & 21 & 9 & $<0.05$ & 30 \\
\hline
\end{tabular}

push the defender away from the copulation position (supplementary materials S1 and S2). In E. malaccana, pushing also involved the challenger moving his shell lip up and down as he advanced forward, leading to successive thrusts towards the defender (see supplementary materials S1). The defender seemed to adopt a 'mate guarding' role as he rarely fought back but remained in the copulation position. A successful takeover occurred when the challenger pushed away the defender and took over the copulation position, whereas an unsuccessful takeover occurred when the challenger failed to push away the defender and subsequently left the mating pair.

\section{Occurrence and intensity of contests}

In general, $>20 \%$ of individuals of both species were mating at each sampling time during the rising tide, with an insignificant but marginally higher intensity in E. malaccana (mean \pm SD: $31.5 \pm 12.3 \%$ ) than in E. radiata $\left(22.6 \pm 6.6 \%\right.$, ANOVA, species: $F_{1,38}=5.41, p=0.058$; shore effect was insignificant; Fig. 1). Overall, in both species, $>10 \%$ of these matings involved a contest, with a significantly higher intensity on section S2 $(28.8 \pm 24.3 \%)$ than other shore sections (average $12.3 \pm 21.3 \%$, ANOVA, shore (species): $F_{6,210}=3.687, p<0.01$; species effect was insignificant; Fig. 1). Males of both species rarely made mistakes by 'mating' with individuals of another species in both $E$. malaccana (5 out of 606 pairs from all quadrats) and $E$. radiata (7 of 681 pairs).

\section{Effect of male and female sizes on contest outcome and duration}

As all contests involved two males on the shell of a female, significantly more cases were found where the challenger was larger than the defender in E. radiata, but not in $E$. malaccana (Table 1). More successful takeovers occurred in $E$. radiata (27 of 30 cases), but an equal number of successful and failed takeover attempts were recorded in $E$. malaccana (15 of 30 cases for both successful and failed takeovers). As the difference in size between the challenger and defender increased, the challenger was more likely to win in contests between $E$. malaccana males (binary logistic regression: $\chi^{2}=5.75, p<0.01$, Fig. 2). For E. radiata, there was a 'perfect separation' (i.e. all three of the nonsuccessful takeovers were by challengers far smaller (29$48 \%$ ) than the snails already mating, and all successful takeovers were from challengers of similar size or larger than those already mating (Fig. 2), indicating a similar, but stronger effect of size difference on contest outcome in $E$. radiata than seen in E. malaccana. In E. malaccana, a challenger has less than half the chance of winning the contest 
Fig. 2 Relationships between the asymmetry in male size on chance of the challenger taking over the copulation position from the defender in E. malaccana and E. radiata
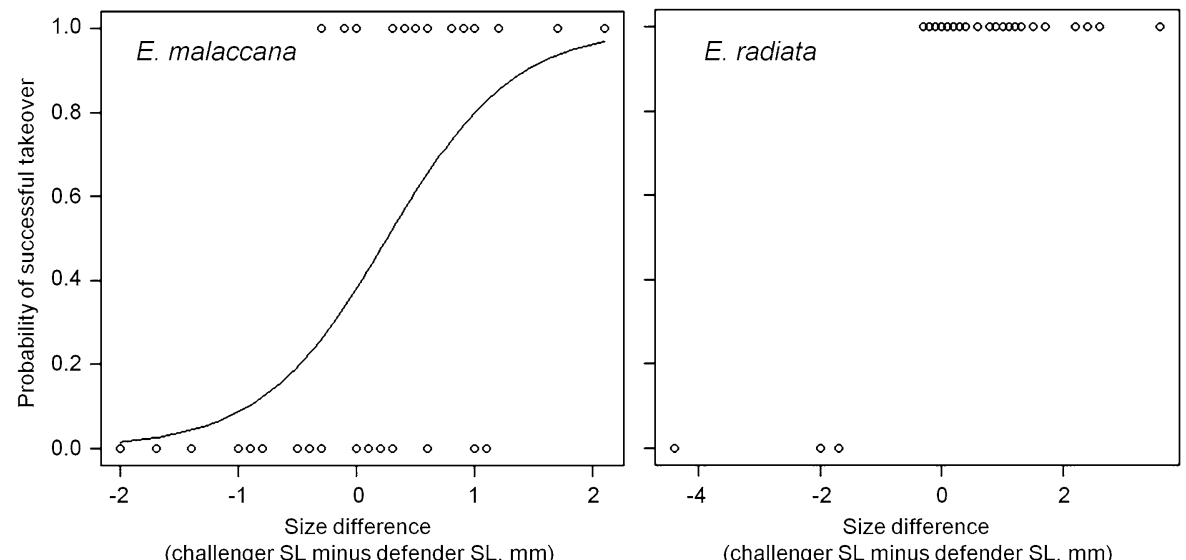

(challenger SL minus defender SL, mm)
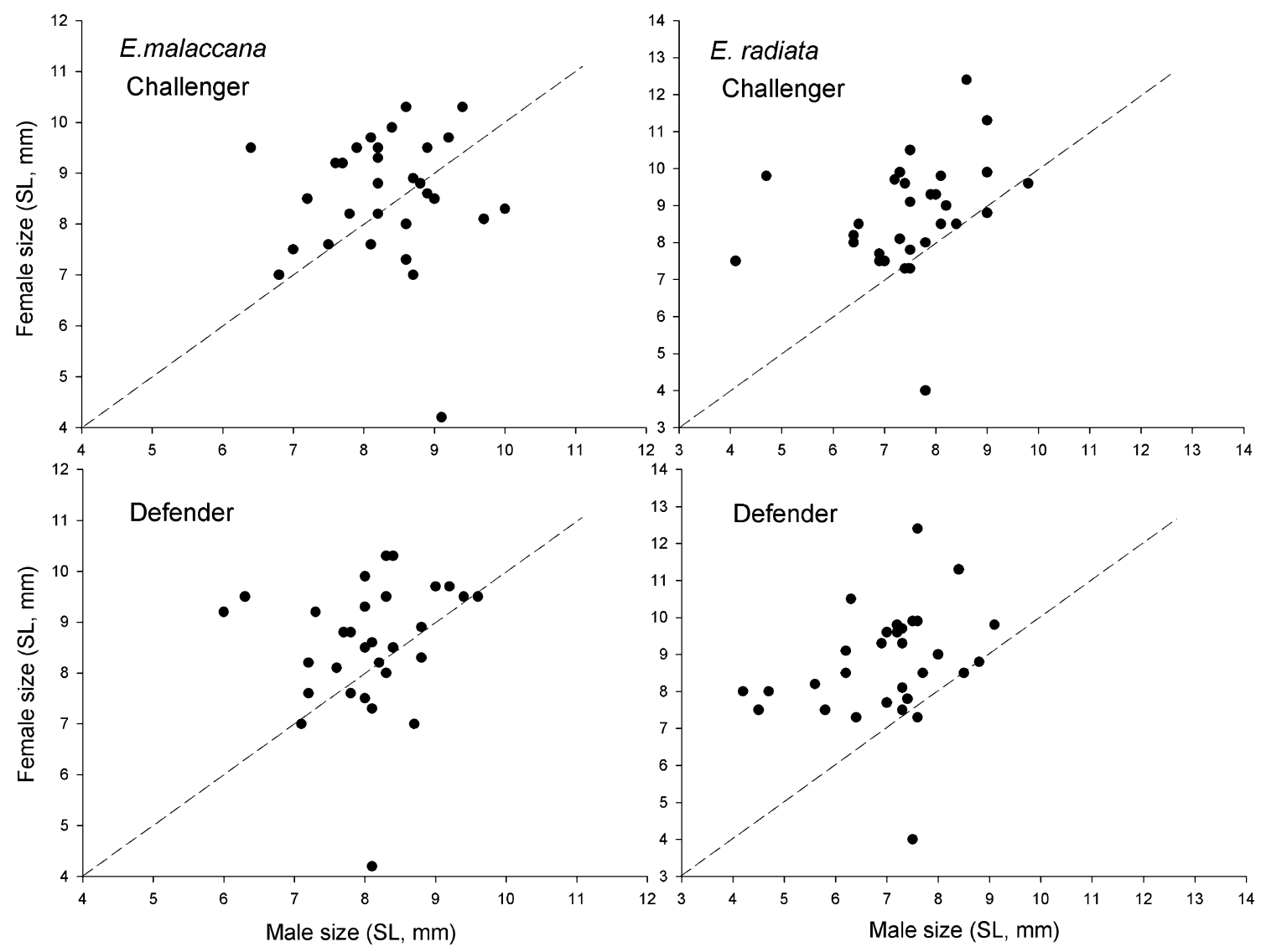

Fig. 3 Size of female versus sizes of challenger and defender in E. malaccana and E. radiata in mating contests. Dashed lines are lines of equity between male and female sizes

if there is no difference in size between the challenger and defender (Fig. 2). In contrast, all challengers won their contests if they were of similar size (up to $0.3 \mathrm{~mm}$ smaller) as the defenders in E. radiata (Fig. 2). E. radiata also appeared more selective about the contests they entered, with significantly fewer cases of a smaller challenger attacking a larger defender than cases of a larger challenger attacking a smaller defender (Table 1; Fig. 2). There were, however, two cases in E. radiata where a smaller challenger lost the contest but then moved to a position behind the larger defender and remained there until the defender finished copulation, whereupon the smaller male mounted and copulated with the female.

Female size had no effect on the contest outcome in both species (binary logistic regressions: both $p>0.05$ ). Almost all (26 of 30 in E. malaccana and 27 of 30 in E. radiata) 

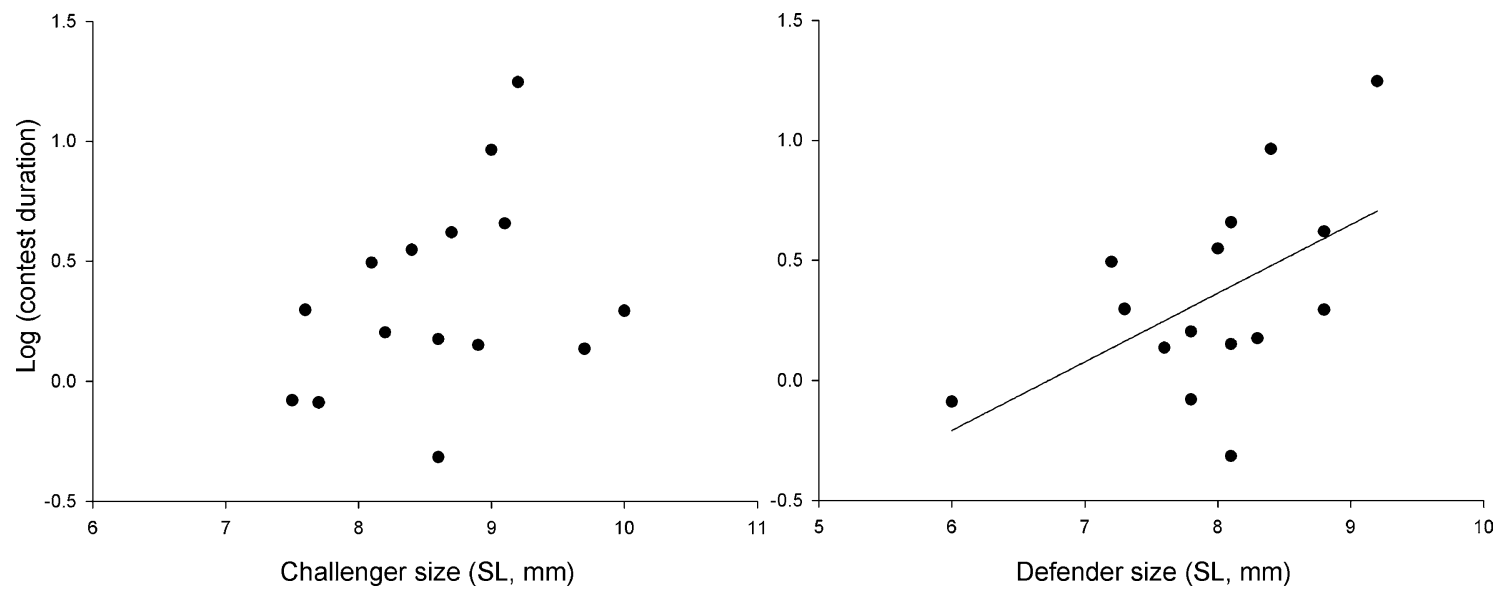

Fig. 4 Relationship between either challenger or defender sizes and contest duration in successful takeovers in E. malaccana. Regression line indicates significant positive linear relationship only between defender size and contest duration, which indicates that a contestant only has information about its own fighting ability

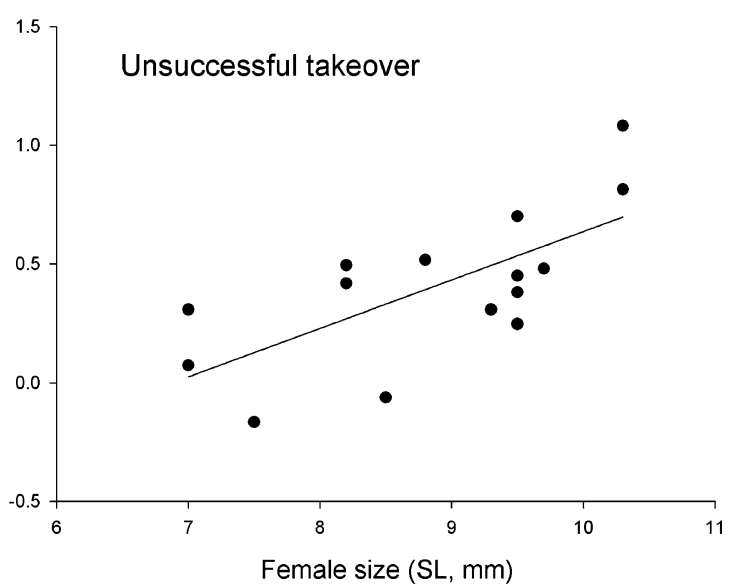

vers but not successful takeovers, suggesting that challengers were better at assessing female quality than defenders

E. malaccana, which indicates that males were exhibiting pure self-assessment. Nor were there significant relationships in other analyses of contest duration against male size in either species (regressions: all $p>0.05$ ). No significant relationships were also found in analyses of contest duration against female size in both species (regressions: all $p>0.05$ ), with the exception of a significant positive relationship (regression: $F_{1,13}=11.74, r^{2}=0.475, \beta=0.689$, $p<0.01$ ) between contest duration and female size in unsuccessful takeovers (i.e. when challengers lost) but not in successful takeovers (when defenders lost) in E. malaccana $\left(F_{1,12}=0.265, r^{2}=0.022, \beta=-0.147, p=0.616\right.$, Fig. 5), suggesting that in E. malaccana, challengers were better able to assess the resource value (i.e. female quality) than the defenders. 


\section{Discussion}

Contests occur in both E. malaccana and E. radiata, and in both species, size is a reliable predictor of the likelihood of successful takeover, indicating that, as in many other animals, size is an important component of RHP (reviewed by Arnott and Elwood 2009). Given that time and energy can be wasted in unsuccessful takeover attempts, selection will favour the ability to assess the size of rivals before a male decides to initiate a contest (Morrell et al. 2005; Arnott and Elwood 2009). This prior assessment seems to be the case in $E$. radiata where challengers generally only entered into contests with defenders smaller than themselves. A similar strategy has also been demonstrated in the hermit crab, Pagurus bernhardus, in which attacking individuals were usually larger than the defending individuals in contests over the occupancy of shells (Elwood et al. 2006). If, as a result of pre-assessment, the challengers are likely to win contests in E. radiata, this may explain why $E$. radiata, despite having a female-biased population, exhibited a similar incidence of male fighting as $E$. malaccana. The mechanism for how such size assessment occurs requires further investigation, but it may be based on the mucus trails of the rivals rather than visual cues, as these snails generally have limited visual ability (Seyer 1992). In some littorinid species, males are able to detect female size from their mucus trails (e.g. Littorina saxatilis, Johannesson et al. 2008; Littorina fabalis, Saltin et al. 2013; L. ardouiniana, $\mathrm{Ng}$ and Williams 2014). Males of both E. malaccana and E. radiata also preferentially follow mucus trails of females larger than themselves and, as a result, generally mount females larger than themselves ( $\mathrm{Ng}$ et al. in submission). This mate-searching selection would explain why females of both species were usually larger than the challengers and defenders in the contests observed.

The male-male contests of the two rocky shore snails, where a challenger takes over the copulation position from a defender, are similar to those described in other taxa such as amphipods (Ward 1983; Dick and Elwood 1990; Prenter et al. 2006). The behaviour of E. malaccana, where the challengers used both their shell lip and snout to push the defenders, also matches observations in two other littorinid species: L. ardouiniana ( $\mathrm{Ng}$ and Williams 2014) and Littorina planaxis (= L. keenae) (Gibson 1965). Despite belonging to a different family, male West Indian fighting conches, Strombus pugilis, also adopt a similar 'fighting' strategy using the shell lip and extended proboscis to attack other males (Bradshaw-Hawkins and Sander 1981), whereas the more subdued attacks of $E$. radiata, which do not involve thrusts with the shell, are similar to another littorinid, Littoraria melanostoma (Ng 2013).
If the up and down movement of the shell lip can be considered stronger male aggression (as compared to snoutpushing only), this difference in aggression between species may be related to female availability (Simmons 1986). Populations of $E$. radiata generally have a more femalebiased sex ratio than E. malaccana (Mak 1996; $\mathrm{Ng}$ et al. in submission). The opportunities to encounter females will, therefore, be greater for male $E$. radiata, which may reduce the importance of enhanced aggression when competing for females as compared to male E. malaccana, where opportunities to encounter females may be limiting. It is, however, counterintuitive that the attacks using shell thrusts in $E$. malaccana were less successful than the more subdued attacks of E. radiata. In E. malaccana, when the sizes of challenger and defender were similar, defenders had a positional advantage (i.e. were more likely to win the contest by occupying the copulation position) over challengers but in the same situation all challengers won the contests in E. radiata. Such a positional advantage of defenders in E. malaccana has also been reported in amphipods (Dick and Elwood 1990) in that defenders, even when disadvantaged by size, were still more likely to win contests because of their precedence in holding the females. Given that females may be limiting in E. malaccana, it is possible that selection may also favour defenders that are tenacious and prepared to invest energy into the contest to defend their resource, resulting in an 'arms-race'-type scenario between the challenger and defender (Emlen 2008).

In fact, if a defender has already invested in locating and securing a female, this may explain why the defender would be highly motivated to defend his resource because the female will now have a higher perceived resource value (Kokko et al. 2006; Arnott and Elwood 2008). We speculate that in $E$. radiata, the opportunity cost (in terms of maximizing number of matings with females) for the defenders to defend the females may be higher than in E. malaccana in a female-biased population, and therefore, males may benefit from quickly giving up any contest upon attack in E. radiata. Males of $E$. radiata also generally mated with females less frequently within their activity window (this study) and had a much shorter $(\sim 3 \times)$ copulation duration than E. malaccana ( $\mathrm{Ng}$ et al. in submission). Male $E$. radiata, therefore, do not seem to invest as much as male E. malaccana in each copulation event/attempt, and hence, costs (at least in terms of time) associated with giving up matings may be lower.

There was some evidence that challengers in E. malaccana were able to assess resource value (female size) in the contests, as they were less likely to retreat when females were larger, whereas this pattern was not observed in defenders (i.e. the decision to retreat was not influenced by female size). This behaviour pattern reveals that 
challengers are prepared to accept higher costs when the resource quality is higher (Arnott and Elwood 2008). Apart from resource assessment, there was also some evidence of a pure self-assessment strategy of RHP in E. malaccana, as described in other taxa such as amphipods (Dick and Elwood 1990; Prenter et al. 2006), chameleons (Stuart-Fox et a1. 2006) and fig wasps (Moore et al. 2008). This assessment strategy infers that a contestant has information about its own fighting ability but not that of its rival, and hence, contestants retreat when they reach their own self-assessed limits (Taylor and Elwood 2003; Arnott and Elwood 2009).

Although 'fighting' behaviour has been reported in several littorinids, there are species in which male-male aggressive behaviour seems to be absent (e.g. Littorina littorea, Erlandsson and Johannesson 1994; L. fabalis and L. saxatilis, $\mathrm{Ng}$ unpubl. observation). It is unclear at this stage why there is such interspecific behavioural variation in this family, but we speculate that lifetime mating opportunities may be a plausible explanation. The mating opportunities of Echinolittorina and Littoraria species in Hong Kong, for example, are heavily constrained by physical factors on these tropical shores, such as heat and desiccation stresses (see Williams and Morrittt 1995). The two Echinolittorina species in this study mate mostly during the rising tide, and when the tide is receding, there is high selection pressure for them to search for refuges and aggregate to avoid thermal and desiccation stresses (Williams 1994; Stafford et al. 2008, 2012). This constrained behaviour is in contrast to Littorina species in temperate regions, which may have a longer activity window due to the more benign physical conditions (e.g. female $L$. saxatilis have been suggested to be 'over-mated' because their mating activities are less constrained by thermal stress during ebbing tides, and they remain reproductively active all year, Johannesson et al. 2010) and are, therefore, likely to have greater lifetime mating opportunities.

Currently, only a few studies have reported contest behaviour in gastropods (i.e. Bradshaw-Hawkins and Sander 1981; Gibson 1965; Zahradnik et al. 2008; Ng and Williams 2014), and most of these studies have not examined how traits related to RHP contribute to contest outcome. The accumulated evidence indicates that physical contests can be common in marine gastropods and take many forms even in co-occurring, congeneric species. Importantly, it appears that both male and female sizes are important factors in determining contest outcomes and hence individual fitness in these gastropods.

Acknowledgments Permission to work at the Cape d' Aguilar Marine Reserve was granted by the Agriculture, Fisheries and Conservation Department of the Hong Kong SAR Government (Permit No.: (143) in AF GR MPA 01/5/2 Pt.13). Two reviewers are thanked for providing valuable comments and suggestions on the manuscript. We also thank Ms Cecily Law, The Swire Institute of Marine Science, HKU, for technical support.

\section{References}

Andersson M (1994) Sexual selection. Princeton University Press, Princeton

Arnott G, Elwood RW (2008) Information gathering and decision making about resource value in animal contests. Anim Behav 76:529-542

Arnott G, Elwood RW (2009) Assessment of fighting ability in animal contests. Anim Behav 77:991-1004

Bradshaw-Hawkins VI, Sander F (1981) Notes on the reproductive biology and behavior of the West Indian fighting conch Strombus pugilis Linnaeus in Barbados with evidence of mate guarding. Veliger 24:159-164

Briffa M, Hardy ICW, Gammell MP, Jennings DJ, Clarke DD, Goubault M (2013) Analysis of animal contest data. In: Hardy ICW, Briffa M (eds) Animal contests. Cambridge University Press, Cambridge, pp 47-85

Dick JTA, Elwood RW (1990) Symmetrical assessment of female quality by male Gammarus pulex (Amphipoda) during struggles over precopula females. Anim Behav 40:877-883

Elwood RW, Pothanikat RME, Briffa M (2006) Honest and dishonest displays, motivational state and subsequent decisions in hermit crab shell fights. Anim Behav 72:853-859

Emlen DJ (2008) The evolution of animal weapons. Annu Rev Ecol Evol Syst 39:387-413

Erlandsson J, Johannesson K (1994) Sexual selection on female size in a marine snail, Littorina littorea (L.). J Exp Mar Biol Ecol 181:145-157

Erlandsson J, Kostylev V (1995) Trail following speed and fractal dimension of movement in a marine prosobranch Littorina littorea during a mating and a non-mating season. Mar Biol 122:87-94

Gibson DG (1965) Mating behaviour in Littorina planaxis Philippi (Gastropoda: Prosobranchiata). Veliger 7:134-139

Hardy ICW, Briffa M (2013) Animal contests. Cambridge University Press, Cambridge

Johannesson K, Havenhand JN, Jonsson PR, Lindegarth M, Sundin A, Hollander J (2008) Male discrimination of female mucus trails permits assortative mating in a marine snail species. Evolution 62:3178-3184

Johannesson K, Saltin SH, Duranovic I, Havenhand JN, Jonsson PR (2010) Indiscriminate males: mating behaviour of a marine snail compromised by a sexual conflict? PLoS One 5:e12005

Kokko H, Lopez-Sepulcre A, Morrell LJ (2006) From hawks and doves to self-consistent games of territorial behavior. Am Nat 167:901-912

Mak YM (1996) The ecology of the high-zoned littorinids Nodilittorina trochoides $N$ radiata and $N$ vidua on rocky shores in Hong Kong. PhD thesis, The University of Hong Kong, Hong Kong

Mak YM, Williams GA (1999) Littorinids control high intertidal biofilm abundance on tropical Hong Kong rocky shores. J Exp Mar Biol Ecol 233:81-94

Marshall DJ, McQuaid CD, Williams GA (2010) Non-climatic thermal adaptation: implications for species' responses to climate warming. Biol Lett 6:669-673

McQuaid CD (1996) Biology of the gastropod family Littorinidae. II. Role in the ecology of intertidal and shallow marine ecosystems. Oceanogr Mar Biol Ann Rev 34:263-302

Moore JC, Obbard DJ, Reuter C, West SA, Cook JM (2008) Fighting strategies in two species of fig wasp. Anim Behav 76:315-322

Morrell LJ, Backwell PRY, Metcalfe NB (2005) Fighting in fiddler crabs Uca mjoebergi: what determines duration? Anim Behav 70:653-662

Ng TPT (2013) Reproductive traits and sexual selection in the mangrove littorinid snails Littoraria ardouiniana and $L$ melanostoma. $\mathrm{PhD}$ thesis, The University of Hong Kong, Hong Kong 
Ng TPT, Williams GA (2012) Contrasting reproductive traits in two species of mangrove-dwelling littorinid snails in a seasonal tropical habitat. Invert Biol 131:177-186

Ng TPT, Williams GA (2014) Size-dependent male mate preference and its association with size-assortative mating in a mangrove snail, Littoraria ardouiniana. Ethology 120:995-1002

Ng TPT, Davies MS, Stafford R, Williams GA (2011) Mucus trail following as a mate-searching strategy in mangrove littorinid snails. Anim Behav 82:459-465

Ng TPT, Saltin SH, Davies MS, Johannesson K, Stafford R, Williams GA (2013) Snails and their trails: the multiple functions of trailfollowing in gastropods. Biol Rev 88:683-700

Parker GA (1974) Assessment strategy and the evolution of fighting behaviour. J Theor Biol 47:223-243

Prenter J, Elwood RW, Taylor PW (2006) Self-assessment by males during energetically costly contests over precopula females in amphipods. Anim Behav 72:861-868

Reid DG (1986) The littorinid molluscs of mangrove forests in the Indo-Pacific region: the genus Littoraria. British Museum (Natural History), London

Reid DG (1989) The comparative morphology phylogeny and evolution of the gastropod family Littorinidae. Philos Trans R Soc B 324:1-110

Reid DG, Dyal P, Williams ST (2012) A global molecular phylogeny of 147 periwinkle species (Gastropoda Littorininae). Zool Scr 41:125-136

Saltin SH, Schade H, Johannesson K (2013) Preference of males for large females causes a partial mating barrier between a large and a small ecotype of Littorina fabalis (W Turton 1825). J Molluscan Stud 79:128-132

Seyer J-O (1992) Resolution and sensitivity in the eye of the winkle Littorina littorea. J Exp Biol 170:57-69
Simmons LW (1986) Inter-male competition and mating success in the field cricket Gryllus bimaculatus (De Geer). Anim Behav 34:567-579

Stafford R, Davies MS, Williams GA (2007) Computer simulations of high shore littorinids predict small-scale spatial and temporal distribution patterns on real rocky shores. Mar Ecol Prog Ser 342:151-161

Stafford R, Davies MS, Williams GA (2008) Self-organization of intertidal snails facilitates evolution of aggregation behavior. Artif Life 14:409-423

Stafford R, Davies MS, Williams GA (2012) Cheats in a cooperative behaviour? Behavioural differences and breakdown of cooperative behaviour in aggregating littorinids. Mar Ecol 33:66-74

Stuart-Fox DM, Firth D, Moussalli A, Whiting MJ (2006) Multiple signals in chameleon contests: designing and analysing animal contests as a tournament. Anim Behav 71:1263-1271

Taylor PW, Elwood RW (2003) The mismeasure of animal contests. Anim Behav 65:1195-1202

Ward PI (1983) Advantages and disadvantages of large size for male Gammarus pulex. Behav Ecol Sociobiol 14:69-78

Williams GA (1994) Grazing by high-shore littorinids on a moderately exposed tropical rocky shore. In: Morton B (ed) The malacofauna of Hong Kong and Southern China III: proceedings of the third international workshop on the Malacofauna of Hong Kong and Southern China. Hong Kong University Press, Hong Kong, pp 379-389

Williams GA, Morrittt D (1995) Habitat partitioning and thermal tolerance in a tropical limpet, Cellana grata. Mar Ecol Prog Ser 124:89-103

Zahradnik TD, Lemay MA, Boulding EG (2008) Choosy males in a littorinid gastropod: male Littorina subrotundata prefer large and virgin females. J Molluscan Stud 74:245-251 